\title{
IMAGE-BASED SURVEYING AND MODELING OF THE UNPROTECTED ARCHITECTURAL HERITAGE - ST. RUDOLF'S CHURCH IN BANOSTOR
}

\author{
V. Stojakovic ${ }^{\text {a, } *}$, I. Bajsanski ${ }^{\text {a }}$ \\ ${ }^{a}$ Department or Architecture, Faculty of Technical Sciences, University of Novi Sad, Trg Dositeja Obradovica 6, \\ 21000 Novi Sad, Serbia - vesna100@uns.as.rs, ivana_m@neobee.net
}

KEY WORDS: Single view reconstruction, photogrammetry, image-based modeling, architectural heritage

\begin{abstract}
:
The aim of this paper is to present image-based recording of the unprotected architectural heritage in threat and its advantages integrating different modeling methods. Considering the construction problems in unprotected buildings we applied variations of low-budget image-based 3D modeling reconstructions techniques and built the complete virtual 3D reconstruction of highly damaged church of St. Rudolph in Banostor. The resulting model reveals many construction and design details that can not be perceived by a simple observing.

In this paper, the importance of integrating a variety of measuring and modeling methodologies in order to achieve digital reconstruction of the unapproachable ruined building is demonstrated. The paper describes survey techniques and workflow, focusing on advantages as well as problems and limitations of each method.
\end{abstract}

\section{INTRODUCTION}

The technical and realization points of view of spatial data recovery are important, but it is necessary to consider a project from its economic perspective (Koutsoudis, Arnaoutoglou and Chamzas, 2006). Photographs can be acquired with no expensive hardware and they contain all the necessary information for the generation of a textured 3D model. Advanced surface measurement algorithms can get similar results to range sensors, but in a cheaper, fastest, portable and simpler way (Remondino, 2011).

Which procedure will be used for the reconstruction depends on the quantity of the available photographs. If just one image is available, in the case if the object does not exist anymore, it is unapproachable or parts of the scene appear in only one image due to occlusions or lack of features to match between images, a single view reconstruction (SVR) is recommended (BräuerBurchardt and Voss, 2001; Stojaković and Tepavčević, 2011; Stojaković and Štulić, 2010).

If more than one image of the same object can be employed in the procedure, the multiple image-based modeling (photogrammetry) is recommended (Yilmaz, et al., 2007; Lingua, Piumatti and Rinaudo, 2003; Schouteden, Pollefeys, et al., 2001; Remondino, 2011; Pavlidis, et al., 2007). Nowadays, available commercial packages provide precise calibration and orientation procedures (Fraser, 2013) and thay are suitable for cultural heritage survay because thay combine the human ability of image understanding with the powerful capacity and speed of computers (Remondino and El-Hakim, 2006).

In order to demonstrate advantages and the importance of image-based modeling approach in architectural heritage surveying, listed techniques are applied to the virtual reconstruction of St. Rudolph's church in Banostor. Architectural heritage is often dangerous or inaccessible due to a construction damages, overgrown vegetation and collapsed building parts, which make recording difficult. In the study of St. Rudolph's church it is shown how the 3D modeling from a single or multiple images is efficiently used as a solution to these problems. This demonstrates the importance of combining different methods in order to achieve digital reconstruction of the unapproachable ruined building.

\subsection{St. Rudolf's chuch in Banostor}

1.1.1 Digital recording, documentation and preservation are demanded as our heritages suffer from on-going attritions and wars, natural disasters, climate changes and human negligence (Remondino, 2011). In the areas where a high risk of human or natural threats exists, the vast number of architectural monuments is ignored and damaged. Cultural heritage disappears and it can be lost for future generations if it is not surveyed and documented (Waldhäusl, 1992).

In the Serbian province of Vojvodina many sacral buildings lost their main purpose because of the dramatic change of sociological ethnics and migrations. These buildings are in peril of being lost and most of them have never been documented. One of the typical examples is the St. Rudolph's Church in Banostor. Banostor is located on edge of Fruska Gora mountain on the banks on the river Danube. From 13th century it was a diocesan center and the fortified town. It the period of the Ottoman Empire, town development was hindered by frequent wars. Town was rebuild and recovered in the period 18-20 century. Four churches for different religions were built in that period. Catholic church dedicated to St. Rudolph, was built in the period 1910-1913 on the land that was the property of earl Rudolf Khotek (1869-1921). The church consists of nave, apsis and the massive side tower with the impressive tower helm. The church is a unique example of Romanism located in this area.

After the Second World War the church loses its purpose. It was used as the storage, refugee shelter and so on, but it was not maintained. Nave roof collapsed first, near the end of the 20th century. The immersive tower helm was in a threat for about a decade. It was not repaired or conserved and it finally collapsed

\footnotetext{
* Corresponding author.
} 
in 2006-2007 during the thunderstorm. The unprotected tower interior is constantly getting more ruined. St. Rudolph's church has never been officially recorded and surveyed. Levels of damage and time periods are shown in Figure 1.

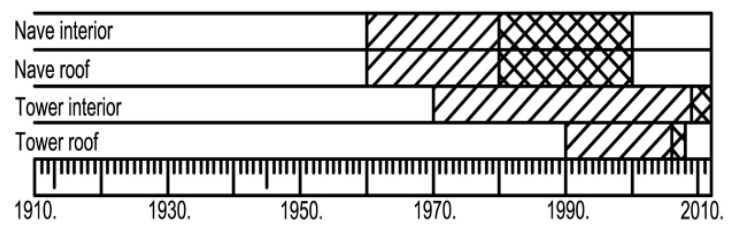

\section{Period in which the element was damaged}

Period in which the element collapsed

Figure 1. Timeline presenting the level of damage.

\section{METHODS AND MATERIALS}

Unprotected cultural heritage in danger should be recorded as efficiently as possible. That means that applied approach has to be low-cost, and that excludes approaches that are time consuming or require expensive equipment. Hence, photographic data are the basis for the extraction of spatial dimensions. The optimal method for registering existing remains of an object is the terrestrial photogrammetry and SVR for the shape reconstruction of collapsed and unapproachable objects parts. Photogrammetry or historical photo reconstruction were used depending on their advantages.

Virtual reconstruction was created in the following phases:

- photogrammetric modeling of church exterior,

- SVR of the tower interior,

- matching of the 3D models,

- modeling of the missing parts and correction of the damaged areas,

- estimation of model reliability.

Available images and material is shown in the Figure 2. Main source for the virtual reconstruction is the series of photographs taken in the year 2005. In that period the nave roof was missing, and the tower helm was damaged. The church was unapproachable due to overgrown vegetation. With a lot of effort it was possible to reach the tower entrance, but its interior could be photographed only from one place, because the narrow entering was blocked by the wall and the huge mass of crumbled material and animal waste. Hence, that photograph is the only source for modeling the tower's interior. The photograph of the staircase is a valuable source for the reconstruction of the tower interior, especially considering the fact that tower helm collapsed shortly after this photo was taken.

Some parts of the church that could not be observed from the photographs taken in 2005 are modeled according to the historical photograph dating from 1913 and a sketch drawing dating from 1983.

\section{IMAGE-BASED MODELING}

Image-based modeling is used as a efficient low-cost approach for the virtual reconstruction of architectural heritage. Depending of the available documentation and object's geometry different types of image-based modeling are recommended Photogrammetry can be used if multiple images of the same structure are available, and SVR if just a single image is available. These two approaches are based on completely different methodology.

For photogrammetric approach series of images in which each point is visible in two or more images are necessary. If the position of the camera is unknown, which is true in most cases that consider reconstruction of architectural heritage. Commercial softer (such as Image Modeler) provides automatic camera pose recovery and the location of the point marked in at least two images. After camera orientation, modeling can be done automatialy or manualy (Barazzetti, Scaioni and Remondino, 2010; Barazzetti et al., 2011; Haala and Kada, 2010). For primitive like geometric shapes modeilng is efficient and precise even if it is done manually.

SVR is based on using a-priori constraints like linearity, parallelism, perpendicularity, symmetry etc. in addition to information extracted from the photograph (Heuvel van den, 1998). This prior knowledge is essential for disambiguating among the innately many 3D reconstructions that are compatible with a given 2D image (Gonzalez-Aguilera and Gomez-Lahoz, 2008; Lourakis and Argyros 2007). In semiautomated SVR aproaches user is the one who recognises and imports constraints to be used. Assuming that such properties are true, the observer has an imagination of the object shape. Single view reconstruction relays on such information. Same

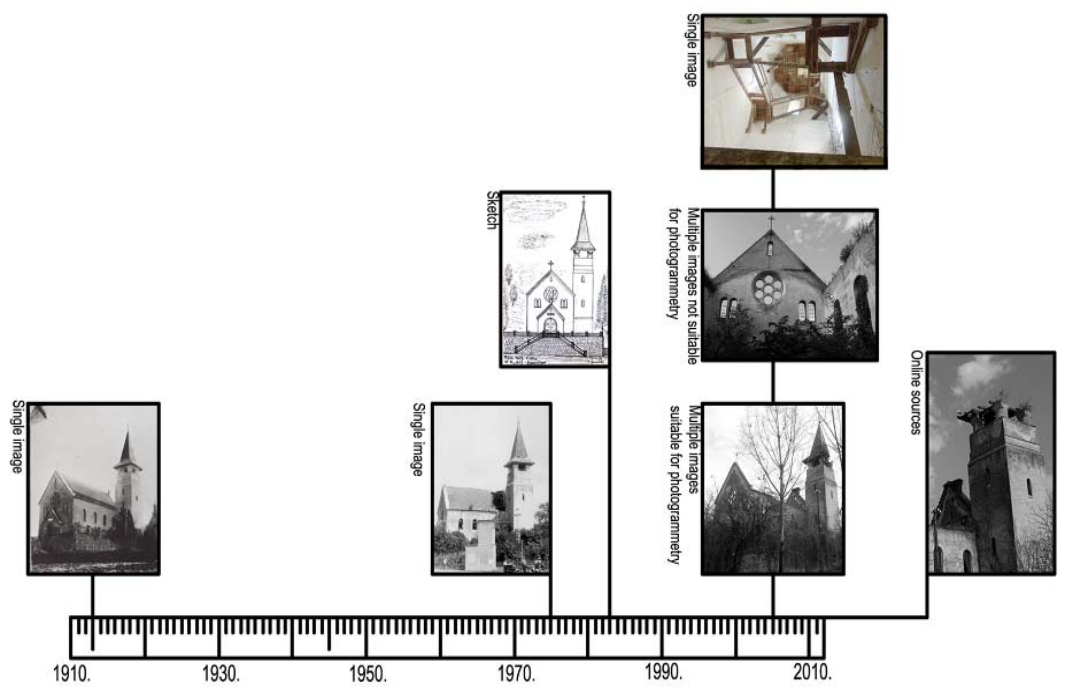

Figure 2. The available material. 
procedure is used in applications for a SVR. Constraints are necessery for camera pose recovery as well as in modeling phase. Commercial SVR packages a usually use three mutually orthogonal directions for camera pose recovery and manual modeling procedures. Most of the applications for 3D modeling and animation also contain tools for such SVR approach. Advantages of such application is that modeling is done in friendly user environment and the texturisation is automated. Limmitations are that such SVR extensions have very limited types of constraint that can be used for camera pose recovery, there is no visualisation of the camera pose recovery process and shape ambiguaty control does not exist.

\subsection{Photogrammetry}

For photogrammetric modeling of St. Rudolph's church a large number of photos are used to cover object's exterior as a whole. Configuration of the terrain, disposition of roads and buildings and the fact that a wide area around the object is unapproachable are reasons why the survey strategy was not planed in advance. An adjustable approach concerning the geometry of camera positions was used, meaning that photographer is not forced to look for parallel views and stereo pair configuration. The strategy of taking photos is that each point to be determined should be intersected by at least two rays of satisfactory intersection angle (Grussenmeyer, Hanke and Streilein, 2002). Church is a free standing building, thus each facade can be photographed from an arbitrary position. Positions of the camera were selected in site. The amateur camera was used because the church was in danger and there was no financial support at the time. The barrel distortion was automatically removed by PT Lens (automatic barrel remove). Convergent bundle of oblique photos, even if they are taken with different focal length, is well suited for commercial packages. Fourteen images were used for the modeling of the nave, and four close-ups were added to assure more detailed model of the tower. In the photogrammetric model the complete textured exterior of the church is presented (except the nave roof that already collapsed).

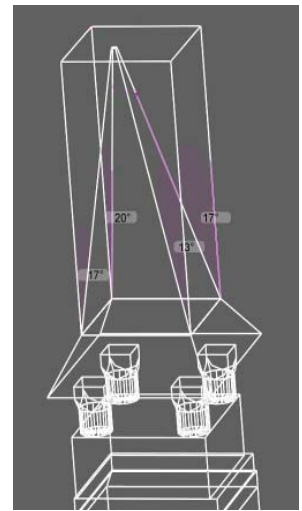

Figure 3. Declination of the tower helm in 2005

Photogrammetric model revealed that the tower helm was already leaning to the one side in 2005 . Vertical axe is modeled to be perpendicular to the tower helm base and to contain the center. The fact that the tower roof top did not belong to the axe indicated that declination of the pyramid exists. Declination was $3^{\circ}$ to the south side and $2^{\circ}$ to the west and angles between each hip rafter of the pyramidal roof and the vertical is shown in Figure 3. That side of the roof was the most damaged, and this is probably the reason why the tower helm collapsed after a few years. In the photogrammetric model complete exterior of the church is presented. Interior of the tower is also imagebased modeled, but from a single view.

\subsection{Single view reconstruction (SVR)}

SVR is a technique for reconstructing the shape characteristics of a scene based on a single photograph. The model of the tower's interior had to be created from a single image taken from the entrance. The entrance in the tower is narrow and one cannot pass much further inside. It is not possible to take several photographs, necessary for photogrammetry, which is why SVR is used for virtual reconstruction of tower's interior. Remains of the staircase, walls and ceiling are captured in the image (Fig. 4). Since image is created with digital camera, barrel distortion, which causes the most obvious errors, is automatically removed.

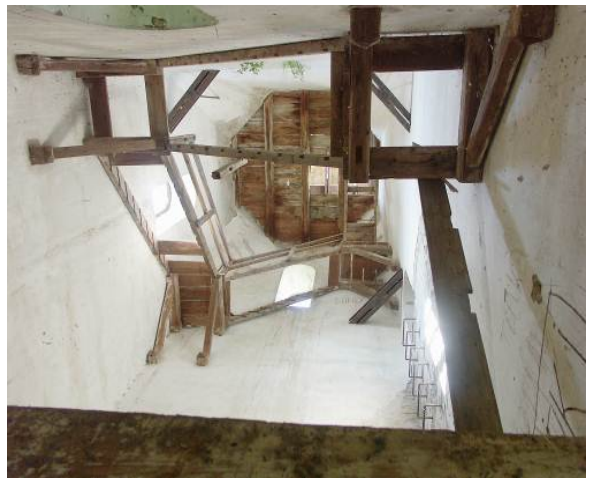

Figure 4. The photograph of the tower interior used for SVR.

First, it is necessary to locate the centre of perspective projection based on its perspective image, in order to reconstruct the shape, size and position of the objects as they appear in real space. Tree mutually orthogonal directions, two horizontal line directions and verticals $(a, b, v)$ are used for the center of perspective location. Corresponding vanishing points $\left(N_{a}, N_{b}, N_{v}\right)$ are detected from the image. Principal point (denoted by $P_{f}$ ) is located near the center of the image, but because the principle point offset it is checked by using the corresponding vanishing lines $\left(\alpha_{n}, \beta_{n}, \chi_{n}\right)$ of two perpendicular vertical planes $\alpha$ and $\beta$ and horizontal plane $\chi$. To determine relative scale of the focal length $(d s)$, planar construction is used (Fig. 5).

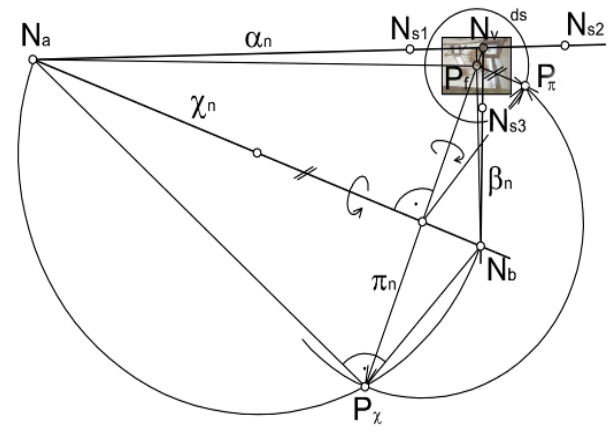

Figure 5. Principal point and focal length construction.

The stair flights have the same slope, and that constraint can also be used for the center of perspective location. However, tools for such advanced orientation methods are not 
incorporated in any commercial software, so the assumption that strait flights have the same slope served as a check for the orientation accuracy. Vanishing points $\left(N_{s 1}, N_{s 2}, N_{s 3}\right)$ of the corresponding flight strings $(s 1, s 2, s 3)$ are noted in the image. In vertical planes $\alpha$ and $\beta$ angles between each string and the vertical is measured. Measured slope is $55^{\circ}$ (angle between string and horizontal is $35^{\circ}$ ) (Fig. 6). It varied $\pm 3^{\circ}$ and that will be later used to check orientation accuracy.

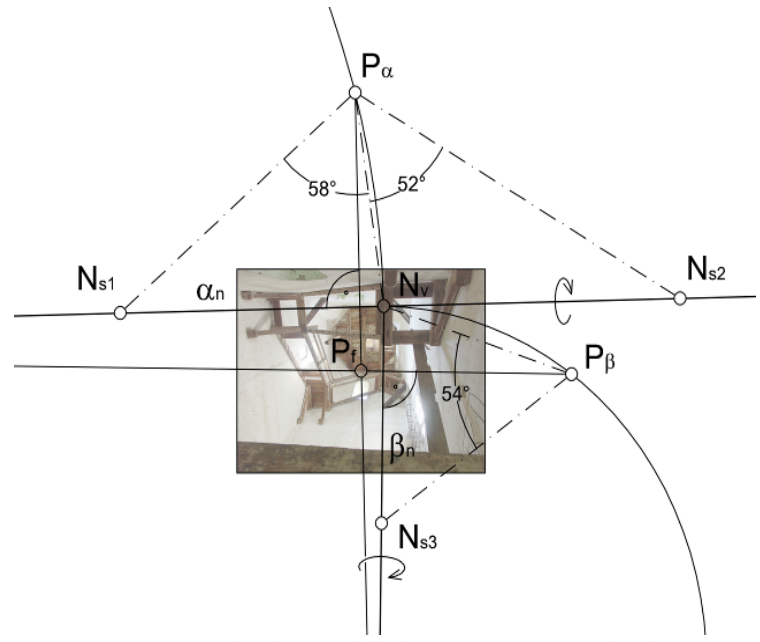

Figure 6. The slope of flights - orientation check.

The process of modeling from a single view has to be carefully planed in order to avoid a problem of a single image ambiguity. Due to a single view ambiguity, the height of the tower could not be directly determined. Walls are not vertical in the upper area, and the slope angle is unknown. The only way to measure the slope of the walls is to introduce symmetry constraint, explicitly to intersect the rectified octagonal ceiling $\left(T_{1}^{C}-T_{8}^{C}\right)$ and imaginary central vertical axe of the tower $\left(v^{C}\right)$ (Fig. 7).

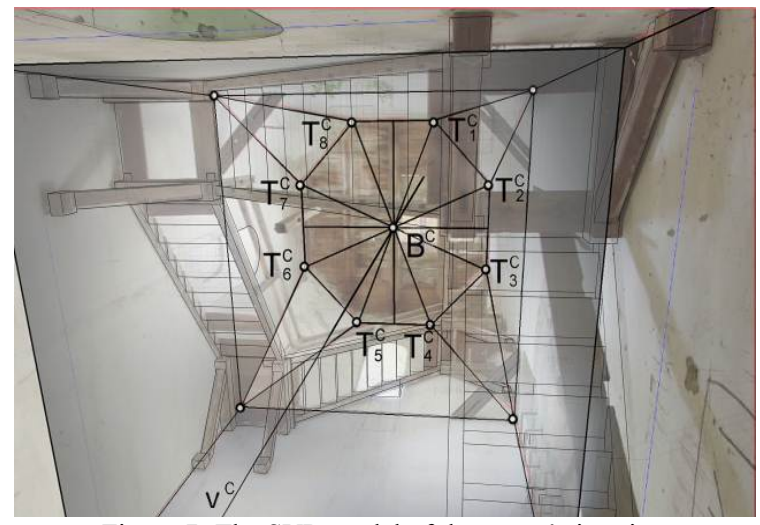

Figure 7. The SVR model of the tower's interior.

In the process of modeling the staircases, it was assumed that all flights have the same slope. Hence, the instance clones were used in order to match the image as much as possible. Complete staircases reconstruction was done by framing and multiplying fliers and landings of existing parts. Two highest flights are partly attached to the sloped part of the wall. The model reveals that constructors solve this problem differently for these two flights. In the lower one, one string is rotated, which produced the uneven width of the fliers. In the higher one the fliers are even but the whole flight is narrower than the others. Part of construction that leads to the roof collapsed, so we do not know whether there was a simple opening in the ceiling or some additional landing existed to ease the exit to the roof. Thus, we modeled just the existing part, strings and two lowest fliers.

Since the base of the tower is not visible in the interior image, and the ceiling is not visible in terrestrial images, combining the photogrammetric model and the SVR model (model of the exterior made by photogrammetric approach and model of the interior created from a single view) was done by matching the tower windows. The model reveals that inside area of a window is wider than the outside (about 1:0,85). Positions of the windows correctly overlapped (mismatches are less than $1 \%$ ).

\section{RESULTS}

Complete process that starts from the data acquisition and ends with the 3D virtual reconstruction of St. Rudolph's church in Banostor is created without measurement, terrain work or special expensive equipment (such as metric cameras, 3D range scanners, etc.). Such 3D model representation, showing object as it looked before any damage, is a virtual reconstruction in three dimensions visible interactively on a computer. For complete virtual reconstruction we used photographs taken with the amateur camera and commercial software that run on standard PC.

Virtual reconstruction provides an overview of the design of the church, its construction and details (Fig.8). Since shapes and relationships between some elements can not be simply perceived from the existing remains (things such as sloped supporting construction of the tower walls, rotation of the stair string, narrower high flights, different landings, height level of the tower ceiling and its relationship with exterior construction, etc.), designer's ideas can be further studied from this 3D model. Model is created to be usable for architectural researchers, so that arbitrary sections can be derived from the virtual reconstruction.

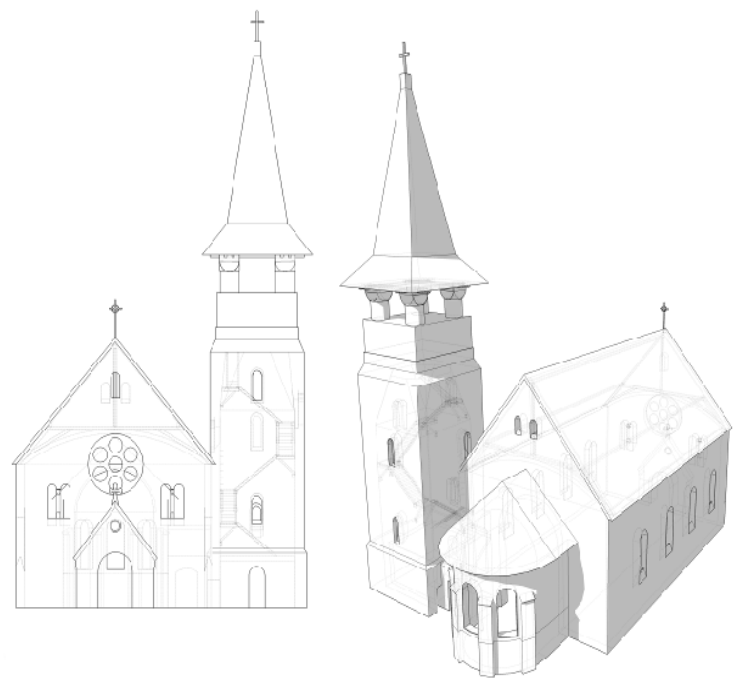

Figure 8 . The 3D virtual reconstruction of the church.

The reliability of the model varies depending on the occlusion in available photo documentation. These variations are presented in Figure 9. Some parts of the church (such as the collapsed roof, nave ceiling, lowest and highest part of the tower staircase, window profiles, windows and doors obscured by vegetation, etc. ) can not be observed from the photographs taken in 2005. These parts are modeled according to the old photograph that was taken in year 1913 and the sketch dating 


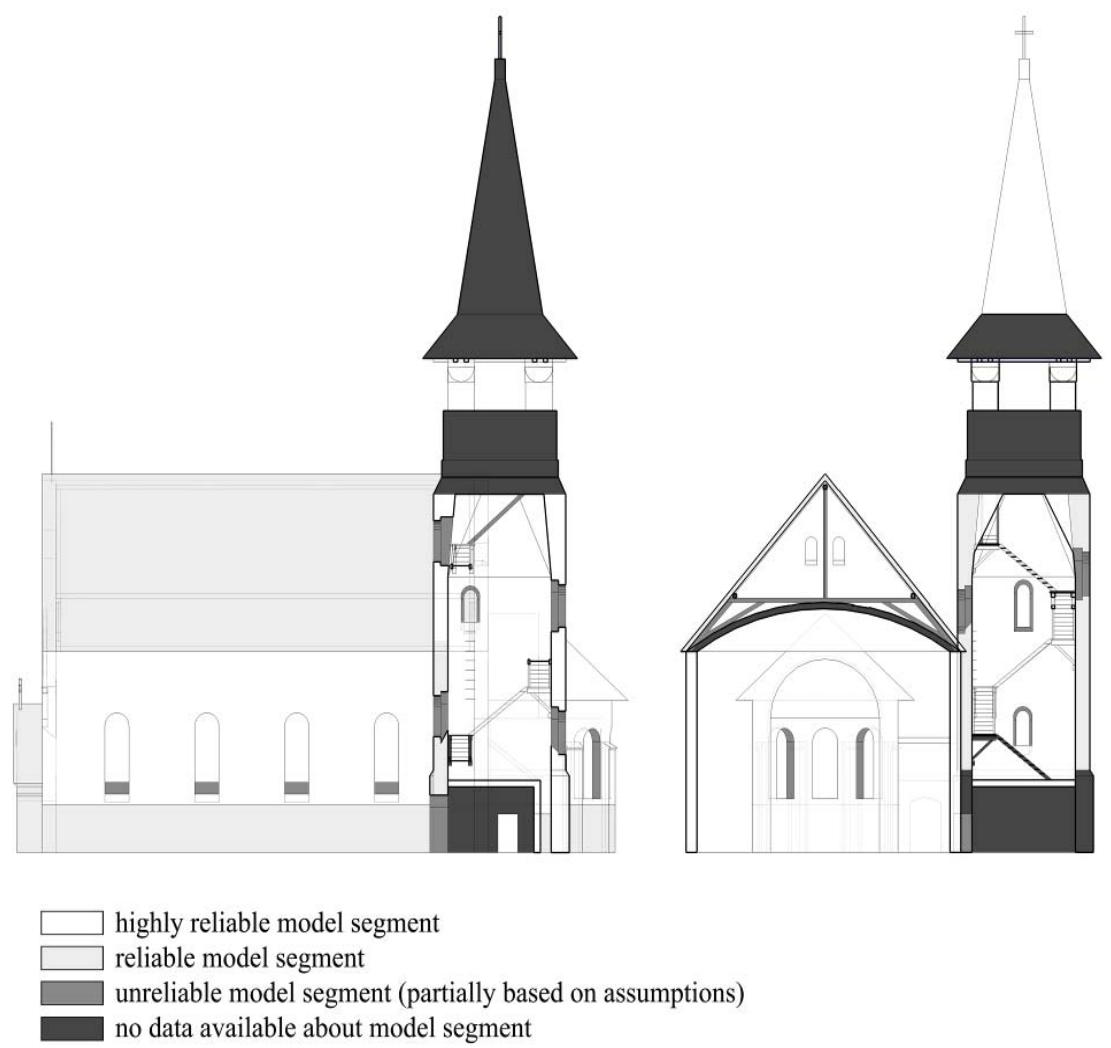

Figure 9. The reliability of the model.

from 1983. However, for some parts no data exists (such as construction of the apsis and tower roofs and inside of the highest tower level, distribution of common rafters of the nave roof, etc.). These details are not modeled.

Although high precision was not a goal of this project, we discuss the accuracy of the model. Since the church can not be measured, we rely on the examination of related projects. To estimate the accuracy of photogrammetric model we used the same procedure (barrel removal, connecting points and modeling), equipment (same camera and focal length) for similar churches. Error in most cases did not go over $1 \%$. In adverse situations (occlusion, sharp intersection angle, etc.) maximal error was 2,2\% (influence of wrong camera parameters or bad image configuration is well studied by Voltolini et al., 2006).

Estimation of accuracy for a SVR is much more difficult, since the used photograph presents a highly complex structure. Considering the variation of the stair slope of the $3^{\circ}$ compared to the height and length of the flight, it is estimated that error in the process of orientation can be up to $2,5 \%$. Mismatches by approximately $2 \%$ and $10 \%$ in exceptional cases can be noticed. Mismatches are shown in the Figure 10. Possible reasons are:

- deviation of a priori constraints (angle between walls may not be exactly $90^{\circ}$, the slope of the flights may vary, wooden construction can be warped, etc.),

- unreliable interpretation of the raster image,

- distortions of the photograph compared to the natural perspective projection,

- imprecision of orientation.

Treatment of error in a historical SVR is well studied in Styliadis and Sechidis (2011), and approach used to decrease error in SVR models proposed in that paper is applicable to this model.
The accuracy of the final 3D model is inferior compared to 3D models that could have been created by geodetic measuring techniques or terrestrial 3D laser range. However, in the case of St. Rudolph's church (and other unprotected buildings in thread) it is obvious that surveying can not be postponed. Nave's roof and ceiling, tower's helm and staircase and apsis roof collapsed and the church has yet not been officially recorded. Model of St. Rudolph's church was made to be usable for architectural studies, so the high precision of restoration documentation is not required. 3D model provides valuable foundation for the studies of shape, construction, design, style, typologies, urban morphologies, etc.

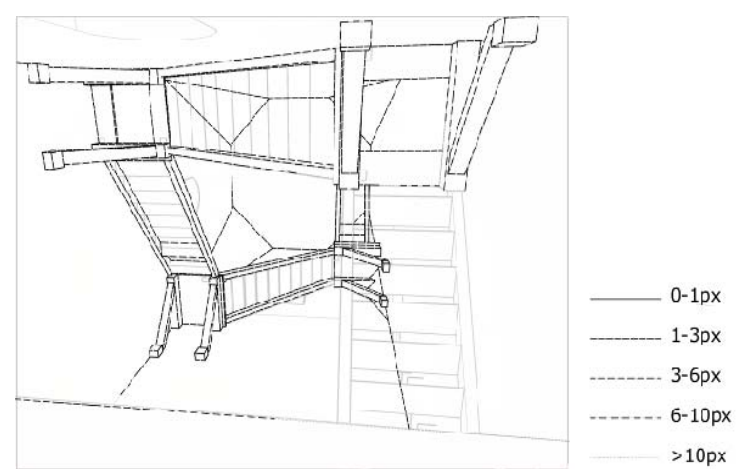

Figure 10. Mismatches of the model and the image. Image resolution is $2560 \mathrm{x} 1920 \mathrm{px}$.

\section{CONCLUSION}

The aim of this paper was to demonstrate the advantages and the importance of image-based modeling techniques for 
documenting the unprotected architectural heritage in threat, which is an efficient tool to preserve the past. Considering the obvious construction problems in the unprotected valuable building we applied variations of sustainable 3D reconstructions techniques, and provided complete virtual reconstruction of highly damaged church of St. Rudolph in Banostor. This also demonstrates the importance of combining different methods in order to achieve digital reconstruction of an unapproachable ruined building.

Photographs were used for a complete virtual reconstruction of the highly damaged building and to derive some important facts about the construction and design that can not be simply perceived from the existing remains. Applied approach prevents valuable data to be lost and saves it for future investigations.

Recording and virtual reconstructions are important in order to promote local heritage and to transmit it to the next generations, as well possibility to explore its space, volumes, design, construction, etc. and to extract classical architectural products such as plans, sections and profiles.

The introduction the 3D nature of survey allows extruding of any type of presentation, such as the orthogonal projection, with vectorial drawings and ortho-rectified images. Virtual models can be used in order to support a future restoration project Digital testing of 3D models is also a preventive method which allows us to detect, measure and track the temporal evolution of some structural problems without the risk of damage.

\section{ACKNOWLEDGEMENT}

This research was supported by the Serbian Ministry of Education, Science and Technological Development.

\section{REFERENCES}

Barazzetti, L., Binda, L., Scaioni, M., Taranto, B., 2011. Photogrammetric survey of complex geometries with low-cost software: Application to the 'G1 temple in Myson, Vietnam. Journal of Cultural Heritage 12, pp. 253-262

Barazzetti, L., Scaioni, M., Remondino F. 2010. Orientation and 3D modelling from markerless terrestrial images: combining accuracy with automation. The Photogrammetric Record 25(132), pp. 356-381.

Bräuer-Burchardt, C., and Voss, K. 2001. Facade reconstruction of destroyed buildings using historical photographs. Proceedings of the XVIII CIPA International Symposium, Potsdam. pp. 543-550.

Fraser, C.S., 2013. Automatic camera calibration in Close Range Photogrammetry. Photogrammetric Engineering \& Remote Sensing, 79(4), pp. 381-388.

Gonzalez-Aguilera, D., and Gomez-Lahoz, J., 2008. From 2D TO 3D Through Modelling Based On A Single Image. The Photogrammetric Record 23(122), pp 208-227.

Grussenmeyer, P., Hanke, K. and Streilein, A. 2002. Architectural photogrammetry. In Digital Photogrammetry, edited by Michel Kasser and Yves Egels, Taylor \& Francis, pp. 300-339.

Haala, M., Kada, M. 2010, An update on automatic 3D building reconstruction, Journal of Photogrammetry and Remote Sensing 65(6), pp. 570-580.
Heuvel, F. van den. 1998. 3D Reconstruction from a Single Image Using Geometric Constraints. ISPRS Journal of Photogrammetry \& Remote Sensing 53, pp. 354-368.

Koutsoudis, A., Arnaoutoglou, F., and Chamzas, C. 2006. On $3 \mathrm{D}$ reconstruction of the old city of Xanthi. A minimum budget approach to virtual touring based on photogrammetry. Journal of Cultural Heritage 8, pp. 26-31.

Lingua, A., Piumatti, P., and Rinaudo, F,. 2003. Digital Photogrammetry: A Standard Approach to Cultural Heritage Survey. The International Archives of the Photogrammetry, Remote Sensing and Spatial Information Sciences XXXIV, pp. $1-6$.

Lourakis, M., and Argyros, A. 2007. Refining Single View Calibration With the Aid of Metric Scene Properties. Proceedings of the 15-th International Conference in Central Europe on Computer Graphics, Visualization and Computer (WSCG'2007), Plzen, pp. 129-134.

Pavlidis, G., Tsiafakis, D., Tsioukas, V., Koutsoudis, A., Arnaoutoglou, F., and Chamzas, C. 2007. Preservation of Architectural Heritage through 3D digitization. International Journal of Architectural Computing (IJAC) in Cultural Heritage 5, pp. 221-237.

Remondino, F. 2011. Heritage Recording and 3D Modeling with Photogrammetry and 3D Scanning. Remote Sensing 3, pp. 1104-1138.

Remondino, F., and El-Hakim, S. 2006. Image-Based 3D Modelling: A Review. The Photogrammetric Record Journal 21, no. 115 , pp. $269-291$.

Schouteden, J., Pollefeys, M, Vergauwe, M., and Vann Gool, L. 2001. Image-Based 3D Acquisition Tool For Architectural Conservation. International Archives for Phtogrammetry and Remote Sensing (IAPRS) XXXIV 5/C7, pp. 301-305.

Stojaković, V., and Tepavčević, B. 2011. Image-based modeling approach in creating 3D morphogenetic reconstruction of Liberty Square in Novi Sad.Journal of Cultural Heritage, 14, pp. 105-110.

Stojaković, V., and Štulić, R. 2010. Virtual Reconstruction of Kljajicevo Chapel. Journal for Geometry and Graphic 14, (10), pp. 81-91.

Styliadis, A., and Sechidis, L. 2011. Photography-based façade recovery \& 3-d modeling: A CAD application in Cultural Heritage. Journal of Cultural Heritage, pp. 243-252.

Voltolini, F., Remondino, F., Pontin, M., and Gonzo, L. 2006. Experiences and Considerations in Image-Based Modeling of Complex Architectures. International Archives for Photogrammetry and Remote Sensing (ISPRS) XXXVI(5), pp. 309-314.

Waldhäusl, P. 1992. Defining the Future of Arcitectural Photogrammetry. International Archives for Photogrammetry and Remote Sensing (ISPRS), pp. 767-770.

Yilmaz, H., Yakar, M., Gulec, S., and Dulgerler, O. 2007. Importance of digital close-range photogrammetry in documentation of cultural heritage. Journal of Cultural Heritage 8, pp. 428-433. 